\title{
Valor Nutritivo da Silagem de Girassol Inoculada com Bactérias Ácido-Láticas ${ }^{1}$ \\ Paulo Henrique Mazza Rodrigues ${ }^{2}$, Tatiana Ferrante de Almeida ${ }^{3}$, Paula Marques Meyer ${ }^{4}$, Laura Maria Oliveira Borgatti ${ }^{5}$
}

\begin{abstract}
RESUMO - Objetivou-se, no presente estudo, avaliar os efeitos da inoculação microbiana da silagem de girassol sobre a digestibilidade total em carneiros. Oito ovinos machos e castrados foram distribuídos em delineamento em reversão simples com seqüência balanceada, com dois períodos sucessivos, totalizando oito animais por tratamento, constituído de silagem de girassol (média de $17,3 \%$ de MS e $13,8 \%$ de PB) controle ou inoculada com S. faecium mais L. plantarum (produto Pioneer 1174). O subperíodo experimental teve duração de 21 dias cada, sendo os cinco últimos destinados à coleta de fezes e urina. A inoculação reduziu a digestibilidade da FDA (45,9\% vs 50,2\%), mas não alterou a digestibilidade total de MS (57,0\% vs 57,8\%), PB (54,6\% vs 55,1\%), EE (63,6\% vs $65,3 \%)$, CNF (81,79\% vs $81,33 \%)$, FDN (43,7\% vs $44,3 \%)$ e amido $(78,7 \%$ vs $74,1 \%)$, NDT (52,5\% vs $53,0 \%)$, a retenção nitrogenada (-0,93 vs $-0,65 \mathrm{~g}$ de N/animal/dia) ou o consumo de MS (2,49 vs $2,54 \%$ do PV).
\end{abstract}

Palavras-chave: bactérias láticas, digestão, ensilagem, Helianthus annuus L., ovinos

\section{Nutritive Value of Sunflower Silage Inoculated with Lactic Acid Bacteria}

\begin{abstract}
The objective of the study was to evaluate effects of microbially inoculated sunflower silage on total digestibility in ovines. Eight animals were assigned to a cross-over design, with two sub-periods ( 8 animals/treatment). Treatments were composed of sunflower silage (17.3\% DM and $13.8 \% \mathrm{CP}$, on average) control or microbially inoculated with S. faecium plus L. plantarum (Pioneer 1174 product). Each experimental sub-period lasted for twenty-one days, where the last five were used for feces and urine collection. The inoculation decreased the digestibility of $\operatorname{ADF}(45.9 \%$ vs $50.2 \%$ ), but it did not influence total digestibility of DM (57.0\% vs $57.8 \%)$, $\mathrm{CP}(54.6 \%$ vs $55.1 \%)$, EE (63.6\% vs $65.3 \%)$, NFC ( $81.79 \%$ vs $81.33 \%)$, NDF (43.7\% vs $44.3 \%)$, starch $(78.7 \%$ vs $74.1 \%)$, TDN (52.5\% vs $53.0 \%), \mathrm{N}$ retention (-0.93 vs $-0.65 \mathrm{~g}$ of $\mathrm{N} / \mathrm{animal} /$ day) or DM intake (2.49 vs $2.54 \%$ of $\mathrm{BW})$.
\end{abstract}

Key Words: ensiling, digestion, Helianthus annuus L., lactic acid bacteria, sheep

\section{Introdução}

A silagem de milho é considerada alimento volumoso padrão para animais ruminantes, com valor nutritivo referencial. Entretanto, sua produção e qualidade são incertas a cada ano, por serem influenciadas pela disponibilidade de água no solo (Nussio, 1991). Portanto, torna-se necessário obter uma cultura alternativa que produza bem sob condições de baixas precipitações e resulte em uma silagem de alta qualidade. Nessas condições, o girassol (Helianthus annuus L.) é apontado como alternativa.

A planta do girassol, apesar de consumir grande quantidade de água durante seu ciclo, é uma das mais tolerantes à escassez hídrica, principalmente por apresentar sistema radicular profundo, que lhe permite exploração de ampla faixa do perfil do solo. Além disso, apresenta um sistema secundário de raízes fasciculadas, a partir da raiz pivotante, que possibilita exploração em sentido horizontal, auxiliando também em sua absorção de água (Pena Neto, 1981). Pesquisas demonstraram que sua produção de grãos é duas vezes menos sensível à seca que a produção de grãos de sorgo e três vezes menos sensível que a produção de grãos de milho (Gonçalves, 1991).

A principal limitação da conservação da cultura de girassol, pelo processo de ensilagem, é o baixo teor de matéria seca próximo ao momento do corte, em torno de 24\% (Vandersall, 1976; McGuffey \& Schingoethe, 1980; Thomas et al., 1982; Valdez et al., 1986; Valdez et al., 1988). A inoculação microbiana tem sido apontada como alternativa para melhorar o

\footnotetext{
1 Projeto financiado pela Fundação de Amparo à Pesquisa do Estado de São Paulo (FAPESP).

2 Depto. de Nutrição e Produção Animal - USP/FMVZ, Av. Duque de Caxias Norte, 225 - CEP. 13630-000, Pirassununga-SP.

E.mail: pmazza@usp.br

3 Bolsista de Iniciação Científica (FAPESP).

${ }^{4}$ Instituto Brasileiro de Geografia e Estatística-IBGE.

${ }^{5}$ Aluna de Doutorado do CENA/USP.
} 
perfil fermentativo e o valor nutricional de silagens úmidas de algumas plantas forrageiras, embora os resultados encontrados sejam bastante variáveis (Bolsen et al., 1989).

Dada a escassez de estudos com inoculação microbina da silagem da planta do girassol, objetivou-se, no presente experimento, avaliar a influência das bactérias ácido-láticas sobre o valor nutritivo da silagem desta planta.

\section{Material e Métodos}

Procedeu-se ao estudo nas instalações do Laboratório de Nutrição de Ruminantes da Faculdade de Medicina Veterinária e Zootecnia da Universidade de São Paulo - Campus de Pirassununga-SP.

A cultura de girassol (Dinamilho M-734) foi plantada no dia 21/04/99, sendo o corte realizado com 99 dias de crescimento, quando as brácteas se encontravam marrons e grande parte das folhas senescente. Uma vez colhida, a planta do girassol foi triturada em partículas de tamanho médio de $1,4 \mathrm{~cm}$, segundo método de mensuração do tamanho de partículas proposto por Heinrichs (1996). A massa foi, então, ensilada em 16 barris plásticos de 200 litros de capacidade (altura aproximada de $90 \mathrm{~cm}$ e diâmetro de $53 \mathrm{~cm}$ ), na densidade de compactação de $500 \mathrm{~kg}$ de silagem $/ \mathrm{m}^{3}$. Os silos receberam revestimento interno com sacos plásticos transparentes que possuíam a função de evitar a entrada de oxigênio. As massas ensiladas receberam dois tratamentos: um controle e outro com adição do inoculante contendo Streptococcus faecium e Lactobacillus plantarum (produto comercial Pioneer 1174, Pioneer Sementes Ltda.), segundo as recomendações do fabricante. O inoculante foi veiculado em água destilada e aplicado sobre a massa por intermédio de um pulverizador manual. De acordo com as especificações do fabricante, o produto testado fornece $9,9 \times 10^{7}$ unidades formadoras de colônia ( $S$. faecium e $L$. plantarum) por grama de forragem.

Após 228 dias de armazenamento em local abrigado, os silos foram abertos para avaliação da digestibilidade aparente em oito ovinos deslanados jovens, machos, castrados, da raça Santa Inês e com peso vivo médio de $31,56 \mathrm{~kg}$ (desvio-padrão de $\pm 1,45 \mathrm{~kg}$ ) no início do experimento. Os animais foram mantidos em gaiolas de estudos metabólicos providas de cocho e bebedouro individuais, fixando a estes bolsas coletoras. Foi utilizado o delineamento em reversão simples com sequiência balanceada e dois subperíodos experimentais (Cochran \& Cox, 1957), com oito repetições por tratamento.

As rações foram compostas das silagens (Tabela 1), adicionadas de $10 \mathrm{~g}$ de suplemento mineral por animal por dia e $10 \mathrm{~g}$ de sal branco $(\mathrm{NaCl})$, fornecidos em duas refeições ( $8 \mathrm{~h}$ e $16 \mathrm{~h})$. O consumo durante o período de coleta de fezes foi restrito a $80 \%$ do ad libitum, durante o período de adaptação. O suplemento mineral apresentou a seguinte composição por kg de produto: $146 \mathrm{~g}$ de $\mathrm{Ca}, 90 \mathrm{~g}$ de $\mathrm{P}, 14 \mathrm{~g}$ de $\mathrm{Mg}$, $15 \mathrm{~g}$ de $\mathrm{S}, 105 \mathrm{~g}$ de Na, $4.800 \mathrm{mg}$ de $\mathrm{Zn}, 1.500 \mathrm{mg} \mathrm{de} \mathrm{Cu}$, $1.200 \mathrm{mg}$ de $\mathrm{Mn}, 2.300 \mathrm{mg}$ de Fe, $150 \mathrm{mg}$ de Co, 180 mg de I, 18 mg de Se e 900 mg de F (máximo).

Cada subperíodo experimental teve duração de 21 dias, sendo os 13 primeiros destinados à adaptação dos animais às dietas. Entre o $9^{\circ}$ e $13^{\circ}$ dia, foi feita a mensuração do consumo; entre o $14^{\circ}$ e e $21^{\circ}$ dia, a restrição do consumo; e entre o $17 \underline{0}$ e $21 \underline{0}$ dia, a coleta de fezes, urina e ingredientes.

As coletas de fezes, obtidas com bolsas coletoras, foram realizadas uma vez ao dia e reunidas para formar uma amostra composta. Após serem pesadas, uma amostra de $10 \%$ foi armazenada a $-15^{\circ} \mathrm{C}$. A urina foi coletada diariamente em baldes plásticos contendo $50 \mathrm{~mL}$ de ácido clorídrico concentrado 1:1.

Tabela 1 - Composição química das silagens de girassol controle e inoculada (porcentagem com base na MS) ${ }^{1}$ Table 1 - Chemical composition of control and inoculated sunflower silage (percentage as DM basis)

\begin{tabular}{lccccccccc}
\hline Silagem & $\mathrm{MS}$ & $\mathrm{PB}$ & $\mathrm{EE}$ & $\mathrm{MM}$ & FDN & FDA & Amido & Ca \\
Silage & $D M$ & $C P$ & $E E$ & Ash & NDF & ADF & Starch & $\begin{array}{c}\text { P } \\
\text { Ca }\end{array}$ \\
\hline $\begin{array}{l}\text { Controle } \\
\begin{array}{l}\text { Control } \\
\text { Inoculada }\end{array}\end{array}$ & 17,46 & 13,71 & 3,55 & 11,24 & 46,86 & 46,42 & 3,28 & 1,72 & 0,17 \\
\begin{tabular}{l} 
Inoculated \\
\hline
\end{tabular} & 17,22 & 13,79 & 3,50 & 10,92 & 47,02 & 44,05 & 3,56 & 1,61 & 0,16 \\
\hline
\end{tabular}

\footnotetext{
${ }^{1}$ MS: matéria seca; PB: proteína bruta; EE: extrato etéreo; MM: matéria mineral; FDN: fibra em detergente neutro; FDA: fibra em detergente ácido; Ca: cálcio; P: fósforo.

${ }^{1}$ MS: dry matter; CP: crude protein; EE: ether extract; NDF: neutral detergent fiber; ADF: acid detergent fiber; Ca: calcium; P: phosphorus.
}

R. Bras. Zootec., v.34, n.1, p.340-344, 2005 
Uma amostra composta, referente a $5 \%$ do total produzido, foi armazenada a $5^{\circ} \mathrm{C}$ até o momento de realização das análises. As análises bromatológicas de MS, PB, EE e MM foram realizadas segundo AOAC (1980) e de FDN e FDA, segundo Goering \& Van Soest (1970). Para análise de FDN, foi omitido o sulfito de sódio, mas adicionada a $\alpha$-amilase. A concentração de amido foi avaliada segundo Pereira \& Rossi (1995), modificando-se este método para a prévia extração dos carboidratos solúveis, segundo método proposto por Hendrix (1993). Determinações dos teores de carboidratos não-fibrosos foram obtidos por diferença. O cálculo dos nutrientes digestíveis totais foi realizado segundo Orskov (1988).

O modelo de análise de variância incluiu efeito de inoculante e efeito de período amostral como causas de variação. Adotou-se o nível de significância de 5\%.

\section{Resultados e Discussão}

A digestibilidade da silagem de girassol (Tabela 2), bem como o NDT, independentemente do tratamento, apresentou valores ligeiramente inferiores aos relatados pelo NRC (1989), provavelmente em virtude de teores em fibra também ligeiramente maiores (Tabela 1), quando comparados aos relatados pelo NRC (1989). A baixa disponibilidade de energia observada na silagem de girassol produzida no presente experimento, com média de 52,7\% de NDT, aliada ao possível estresse do confinamento, resultou em balanço nitrogenado negativo, com perda de aproximadamente 0,8 gramas de nitrogênio/animal/dia, independentemente do tipo de silagem testada.

A adição de inoculantes à silagem de girassol diminuiu a digestibilidade da fibra em detergente ácido $(\mathrm{P}<0,05)$ em $8,5 \%$ (4,3 pontos percentuais). Não foram observados efeitos da inoculação sobre a digestibilidade aparente da matéria seca, proteína bruta, extrato etéreo, carboidratos não-fibrosos, fibra em detergente neutro e amido, bem como sobre os nutrientes digestíveis totais. Não foi observada também alteração sobre a retenção nitrogenada, expressa em gramas de N/dia ou em porcentagem do $\mathrm{N}$ absorvido.

Estudos realizados in vivo para avaliação dos efeitos da inoculação microbiana sobre o valor nutritivo da silagem de girassol são escassos na literatura. Entretanto, esta forragem apresenta composição semelhante à do milho e sorgo, porém maiores teores de extrato etéreo e de fibra em detergente ácido (McGuffey \& Schingoethe, 1980). $\mathrm{O}$ alto teor de umidade também parece ser um fator limitante da ensilagem, quando comparada àquelas forrageiras.

Tabela 2 - Valores de digestibilidade aparente e retenção nitrogenada obtidas com silagens de girassol tratadas ou não com inoculantes ${ }^{1}$

Table 2 - Apparent digestibility values and nitrogen retention obtained with inoculated and control sunflower silages

\begin{tabular}{|c|c|c|c|c|c|}
\hline \multirow[b]{2}{*}{$\begin{array}{l}\text { Variável } \\
\text { Variable }\end{array}$} & \multicolumn{2}{|c|}{$\begin{array}{c}\text { Tratamentos } \\
\text { Treatments }\end{array}$} & \multirow[b]{2}{*}{$\begin{array}{l}\text { Média } \\
\text { Mean }\end{array}$} & \multirow[b]{2}{*}{$\mathrm{CV}(\%)$} & \multirow[b]{2}{*}{$\begin{array}{c}\text { Valor de } \mathrm{P} \\
P \text { value }\end{array}$} \\
\hline & $\begin{array}{c}\text { Controle } \\
\text { Control } \\
\end{array}$ & $\begin{array}{l}\text { Inoculada } \\
\text { Inoculated } \\
\end{array}$ & & & \\
\hline$\overline{M S}(\%)(D M)$ & 57,83 & 57,04 & 57,44 & 3,89 & 0,1792 \\
\hline $\mathrm{PB}(\%)(C P)$ & 55,11 & 54,64 & 54,87 & 4,28 & 0,6942 \\
\hline $\mathrm{EE}(\%)(E E)$ & 65,30 & 63,60 & 64,45 & 5,29 & 0,3352 \\
\hline $\mathrm{CNF}(\%)(N F C)$ & 81,33 & 81,79 & 81,56 & 4,11 & 0,6454 \\
\hline $\mathrm{FDN}(\%)(N D F)$ & 44,27 & 43,68 & 43,97 & 4,78 & 0,5961 \\
\hline $\operatorname{FDA}(\%)(A D F)$ & 50,20 & 45,92 & 48,06 & 6,97 & 0,0001 \\
\hline $\operatorname{Amido}(\%)($ Starch $)$ & 74,12 & 78,66 & 76,39 & 8,87 & 0,1603 \\
\hline $\operatorname{NDT}(\%)(T D N)$ & 53,00 & 52,46 & 52,73 & 4,44 & 0,3911 \\
\hline $\mathrm{RN}(\mathrm{g})(N R)$ & $-0,65$ & $-0,93$ & $-0,79$ & 191,08 & 0,7329 \\
\hline $\mathrm{RN}(\%)(N R)$ & $-13,60$ & $-14,18$ & $-13,89$ & 165,55 & 0,9631 \\
\hline
\end{tabular}

${ }^{1} \mathrm{MS}$ : digestibilidade da matéria seca (\%); PB: proteína bruta (\%); EE: extrato etéreo (\%); CNF: carboidratos não-fibrosos (\%); FDN: fibra em detergente neutro (\%); FDA: fibra em detergente ácido (\%); NDT: nutrientes digestíveis totais (\%); RN(g): retenção nitrogenada (g de N/dia); RN (\%): retenção nitrogenada (em porcentagem do N absorvido/dia); CV: coeficientes de variação (\%); Valor de P: probabilidades estatísticas.

1 DM: digestibility of dry matter (\%); CP: crude protein (\%); EE: ether extract (\%); NFC: non-fibrous carbohydrate (\%); NDF: neutral detergent fiber (\%); ADF: acid detergent fiber (\%); TDN: total digestible nutrients (\%); NR ( $g$ ): nitrogen retention ( $g$ of $N /$ day); $N R(\%)$ : nitrogen retention (percentage of absorbed nitrogen/ day); CV: coefficient of variation (\%); P value: statistical probability.

R. Bras. Zootec., v.34, n.1, p.340-344, 2005 
A diminuição da digestibilidade da FDA observada no presente experimento é semelhante aos resultados observados por Phillip \& Fellner (1992), ao inocularem Lactobacillus plantarum na silagem de grãos de milho de alta umidade. Entretanto, é incompatível ao aumento da digestibilidade da FDN (Schaefer et al., 1989), da MS e da matéria orgânica de silagens da planta do milho (Luther, 1986), bem como ao aumento da digestibilidade aparente da MS, PB, FDN e FDA em silagem de sorgo (Wiedwald et al., 1992) obtidos com a inoculação. Sanderson (1993), Rodriguez et al. (1996) e Daenicke et al. (1999) não observaram efeitos da inoculação microbiana sobre a digestibilidade da silagem de milho ou sorgo, sorgo e milho, respectivamente.

Hunt et al. (1993) verificaram que a inoculação microbiana diminuiu a digestibilidade in vitro da matéria seca da silagem de milho, mas não a digestibilidade in vitro da FDN. Este resultado foi inverso ao apresentado nesta pesquisa, em que se constatou diminuição da digestibilidade in vivo da
FDA, mas não da MS. Esses autores atribuíram os resultados a uma hidrólise parcial da hemicelulose desencadeada com o processo de inoculação microbiana. No caso da cultura de girassol, que é praticamente desprovida de hemicelulose, essa hipótese é rejeitada, embora os teores de FDA estivessem aparentemente reduzidos com a inoculação, indicando possível hidrólise parcial da celulose ou pectina, haja vista o processo de avaliação não-seqüencial à extração com detergente neutro. Entretanto, não foi objetivo do presente experimento avaliar os efeitos da inoculação sobre a composição bromatológica das silagens.

A adição de inoculantes à silagem de girassol não alterou o consumo de matéria seca (Tabela 3). De forma geral, o consumo de matéria seca (média de $2,5 \%$ do peso vivo) pode ser considerado satisfatório, fato que deve ter sido corroborado por fermentações aparentemente normais de ambas as silagens, sem fermentações indesejáveis. Os consumos de matéria seca digestível, de NDT e de FDN também não foram afetados pela inoculação.

Tabela 3 - Valores de consumos de matéria seca, de matéria seca digestível, de nutrientes digestíveis totais e de fibra em detergente neutro obtidos com silagens de girassol tratadas ou não com inoculantes ${ }^{1}$

Table 3 - Values of intakes of dry matter, digestible dry matter, total digestible nutrients and neutral detergent fiber obtained with inoculated or control sunflower silage

\begin{tabular}{|c|c|c|c|c|c|}
\hline \multirow[b]{2}{*}{$\begin{array}{l}\text { Variável } \\
\text { Variable }\end{array}$} & \multicolumn{2}{|c|}{$\begin{array}{r}\text { Tratamentos } \\
\text { Treatments }\end{array}$} & \multirow[b]{2}{*}{$\begin{array}{l}\text { Média } \\
\text { Mean }\end{array}$} & \multirow[b]{2}{*}{$\mathrm{CV}(\%)$} & \multirow[b]{2}{*}{$\begin{array}{c}\text { Valor de } \mathrm{P} \\
\quad P \text { value }\end{array}$} \\
\hline & $\begin{array}{l}\text { Controle } \\
\text { Control }\end{array}$ & $\begin{array}{l}\text { Inoculada } \\
\text { Inoculated }\end{array}$ & & & \\
\hline $\begin{array}{l}\overline{C M S}(\mathrm{~g} / \mathrm{d}) \\
D M I(g / d)\end{array}$ & 775,69 & 737,42 & 756,55 & 22,19 & 0,6755 \\
\hline $\begin{array}{l}\text { CMS (\%PV) } \\
D M I(\% B W)\end{array}$ & 2,54 & 2,49 & 2,52 & 20,50 & 0,8710 \\
\hline $\begin{array}{l}\operatorname{CMSD}(\mathrm{g} / \mathrm{d}) \\
D D M I(g / d)\end{array}$ & 446,77 & 421,30 & 434,03 & 22,28 & 0,6275 \\
\hline $\begin{array}{l}\text { CMSD }(\% \mathrm{PV}) \\
D D M I(\% B W)\end{array}$ & 1,46 & 1,43 & 1,44 & 20,32 & 0,8194 \\
\hline $\begin{array}{l}\text { CNDT }(\mathrm{g} / \mathrm{d}) \\
\text { TDNI }(g / d)\end{array}$ & 409,66 & 387,60 & 398,63 & 22,61 & 0,6515 \\
\hline $\begin{array}{l}\text { CNDT }(\% \mathrm{PV}) \\
\text { TDNI }(\% B W)\end{array}$ & 1,34 & 1,31 & 1,33 & 20,48 & 0,8471 \\
\hline $\begin{array}{l}\operatorname{CFDN}(\mathrm{g} / \mathrm{d}) \\
\operatorname{NDFI}(\mathrm{g} / \mathrm{d})\end{array}$ & 365,31 & 346,44 & 355,87 & 21,11 & 0,6675 \\
\hline $\begin{array}{l}\mathrm{CFDN}(\% \mathrm{PV}) \\
N D F I(\% B W)\end{array}$ & 1,20 & 1,17 & 1,18 & 21,85 & 0,8580 \\
\hline
\end{tabular}

${ }^{1} \mathrm{CMS}$ : consumo de matéria seca; CMSD: consumo de matéria seca digestível; CNDT: consumo de nutrientes digestíveis totais; CFDN: consumo de fibra em detergente neutro; expresso em g/animal/dia (g/d) ou porcentagem do peso vivo (\%PV); CV: coeficientes de variação (\%); Valor de P: probabilidades estatísticas.

${ }^{1}$ DMI: dry matter intake; DDMI: digestible dry matter intake; TDNI: total digestible nutrients intake; NDFI: neutral detergent fiber intake; expressed in g/animal/ day $(\mathrm{g} / \mathrm{d})$ or percentage of body weight (\%BW); CV: coefficient of variation (\%); $P$ value: statistical probability.

R. Bras. Zootec., v.34, n.1, p.340-344, 2005 


\section{Conclusões}

A ausência de efeitos sobre a disponibilidade de nutrientes ou sobre o consumo de matéria seca não permite recomendar a utilização de inoculantes contendo Streptococcus faecium e Lactobacillus plantarum para inoculação da silagem de girassol.

\section{Agradecimento}

Aos técnicos Ari de Castro, Gilson de Godoy e Simi Robassini, pelas análises laboratoriais, e aos funcionários Everson Lázaro e Gilmar Botteon, pelo cuidado incessante com os animais.

\section{Literatura Citada}

ASSOCIATION OF OFFICIAL ANALYTICAL CHEMISTS AOAC. Official methods of analysis. 10.ed. Washington, D.C.: 1980. 1015p.

BOLSEN, K.K.; LAYTINI, A.; HART, R.A. et al. Effect of commercial inoculants on fermentation of 1987 and 1988. Kansas silage crops. Des Moines: Pionner Hi-Bred Int., 1989. p.1-19.

COCHRAN, W.G.; COX, G.M. Experimental designs. 2.ed. New York: John Wiley \& Songs, 1957. 611p.

DAENICKE, R.; JOCHMANN, K.; GADEKEN, D. et al. Influence of lactic acid bacteria as inoculant in corn silage on digestibility of crude nutrients and performance of dairy cows. Landbauforschung Volkenrode, v.49, p.64-69, 1999.

GOERING, H.K.; Van SOEST, P.J. Forage fiber analysis: apparatus, reagents, procedures and some applications. 1.ed. Washington. DC.: ARS-USDA, 1970. p.387-598.

GONÇALVES, N.P. Época, espaçamento, densidade de plantio e irrigação para cultura de girassol. Informe Agropecuário, v.7, p.78-80, 1991.

HEINRICHS, J. Evaluating particle size of forages and TMRs using the Penn State Paticle Size Separator. 1.ed. Philadelphia: The Pennsylvania State University, 1996. 15p.

HENDRIX, D.L. Rapid extraction and analysis of nonstructural carbohydrates in plant tissues. Crop Science, v.33, n.6, p.1306-1311, 1993.

HUNT, C.W.; KEZAR, W.; HINMAN, D.D. et al. Effects of hybrid and ensiling with and without a microbial inoculant on the nutritional characteristics of whole-plant corn. Journal of Animal Science, v.71, p.38-43, 1993.

LUTHER, R.M. Effect of microbial inoculation of whole plant corn silage on chemical characteristics, preservation and utilization by steers. Journal of Animal Science, v.63, p.1329, 1986.

McGUFFEY, R.K.; SCHINGOETHE, D.J. Feeding value of a high oil variety of sunflowers as a silage to lactating dairy cows. Journal of Dairy Science, v.63, p.1109-1113, 1980.
NATIONAL RESEARCH COUNCIL - NRC. Nutrient requirenents of dairy cattle. 6.ed. Washington: National Academy of Sciences, 1989. 157p.

NUSSIO, L.G. Cultura de milho para produção de silagem de alto valor alimentício. In: SIMPÓSIO SOBRE NUTRIÇÃO DE BOVINOS, Piracicaba, 4., 1991, Piracicaba. Anais... Piracicaba: Fundação de Estudos Agrários Luiz de Queiroz, 1991. p.59-168.

ORSKOV, E.R. World animal science: feed science. Amsterdam: Elsevier Science Publishers B.V., 1988. 336p.

PENA NETO, M.P. Girassol: manual do produtor. Cravinhos: Sementes Canti Brasil, 1981. 30p.

PEREIRA, J.R.A.; ROSSI JR., P. Manual prático de avaliação nutricional de alimentos. Piracicaba: Fundação de Estudos Agrários Luiz de Queiroz, 1995. 25p.

PHILLIP, L.E.; FELLNER, V. Effects of bacterial inoculation of high-moisture ear corn on its aerobic stability, digestion, and utilization for growth by beef steers. Journal of Animal Science, v.70, p.3178-3187, 1992.

RODRIGUEZ, A.A.; RUST, S.R.; RIQUELME, E.O. et al. Efecto de aditivos para ensilaje y duracion de exposicion aerobica sobre la degradabilidad in vitro y recuperacion de materia seca de sorgo forrajero ensilado em dos estados de madurez. Archivos Latinoamericanos de Produccion Animal, v.4, p.91-100, 1996.

SANDERSON, M.A. Aerobic stability and in vitro digestibility of microbially inoculated corn and sorghum silages. Journal of Animal Science, v.71, p.505-514, 1993.

SCHAEFER, D.M.; BROTZ, P.G.; ARP, S.C. et al. Inoculation of corn silage and high-moisture corn with lactic acid bacteria and its effect on the subsequent fermentations and on feedlot performance of beef steers. Animal Feed Science and Technology, v.25, p.23, 1989.

THOMAS, V.M.; MURRAY, G.A.; THACKER, D.L. et al. Sunflower silage in rations for lactating Holsteins cows. Journal of Dairy Science, v.65, p.267-270, 1982.

VALDEZ, F.R.; FRANSEN, S.C.; HARRISON, J.H. Cornsunflower intercropping as a silage crop. Journal of Dairy Science, v.69, p.138, 1986 (Supplement 1).

VALDEZ, F.R.; HARRISON, J.H.; DEETZ, D.A. et al. In vivo digestibility of corn and sunflower intercropped as a silage crop. Journal of Dairy Science, v.71, p.1860-1867, 1988.

VANDERSALL, J.H. Sunflower silage for lactating dairy cows. Journal of Animal Science, v.42, p.1583, 1976 (Supplement 1).

WIEDWALD, C.; FROETSCHEL, M.A.; ELY, L.O. et al. Factors influencing utilization of sorghum silage for lactating dairy cattle under heat stress. Journal of Dairy Science, v.74, p.148, 1991 (Supplement 1).

Recebido em: 15/06/03

Aceito em: 09/09/04 